\title{
Invited commentary for asymmetric dimethylarginine (ADMA): Is it a risk factor in the repair of aortic coarctation?
}

Chi Chi Do-Nguyen ${ }^{1}$, Randy Stevens ${ }^{2}$, Juan Ochoa ${ }^{3}$, Amy Throckmorton ${ }^{4}$, and Leonardo Mulinari ${ }^{5}$

${ }^{1}$ Affiliation not available

${ }^{2}$ St. Chrsitopher's Hospital for Children

${ }^{3}$ Hunterdon Medical Center

${ }^{4}$ Drexel University

${ }^{5}$ University of Miami Miller School of Medicine

April 9, 2021

\begin{abstract}
Bas et al. report the clinical measurement, using High Performance Liquid Chromatography (HPLC), of asymmetric dimethyarginine in two groups of patients undergoing aortic coarctation repair.
\end{abstract}

\section{Hosted file}

FINAL Invited Commentary for ADMA.pdf available at https://authorea.com/users/314039/ articles/517342-invited-commentary-for-asymmetric-dimethylarginine-adma-is-it-a-riskfactor-in-the-repair-of-aortic-coarctation 